\title{
Current Trends in Photoprotection - A New Generation of Oral Photoprotectors
}

\author{
Salvador Gonzalez ${ }^{*}, 1,2$, Yolanda Gilaberte ${ }^{3}$, Neena Philips ${ }^{4}$ and Angeles Juarranz ${ }^{5}$ \\ ${ }^{I}$ Dermatology Service, Memorial Sloan-Kettering Cancer Center, New York, USA \\ ${ }^{2}$ Dermatology Service, Ramon y Cajal Hospital, Madrid, Spain \\ ${ }^{3}$ Dermatology Service, Hospital San Jorge, Huesca, Spain \\ ${ }^{4}$ School of Natural Sciences, University College, Fairleigh Dickinson University, Teaneck, NJ, USA \\ ${ }^{5}$ Biology Department, Sciences School, Universidad Autónoma de Madrid, Madrid, Spain
}

\begin{abstract}
This review provides an overview of important concepts and trends in photoprotection. From the use of protective clothing to latest-generation oral photoprotectives, this article covers these topics from two points of view: 1) the physical blockade (absorption and/or reflection) of UV photons by topical sunscreens; 2) topical compounds with antioxidant properties that thereby protect of the consequences of UV-mediated photooxidation. The last section is devoted to the development of strong antioxidant oral compounds and discusses their possibilities as adjuvants in skin protection and repair and regeneration.
\end{abstract}

Keywords: Photoprotection, sunscreens, oral antioxidants, dietary photoprotectants.

\section{INTRODUCTION}

UV filters ("sunscreens") are designed to protect the skin from the harmful effects of solar radiation, particularly the UV band. UV radiation can be roughly divided into two segments according to wavelength: UVB $(\sim 290-320 \mathrm{~nm})$ and UVA $(\sim 320-400 \quad \mathrm{~nm}) . \quad$ UVB is erythematogenic, carcinogenic, induces photoaging and mutagenic damage to nucleic acids, e.g. RNA and DNA. UVA, on the other hand, is also mildly erythematogenic, but promotes ROS (Reactive Oxygen Species) accumulation. ROS also induce direct cell damage, carcinogenesis and contribute to photoaging.

The basic idea underlying photoprotection is to establish a physical barrier between the sun and the skin; hence most of these compounds exert their protective effect when used topically. However, a new trend is emerging, consisting of increasing the basal antioxidant threshold of the body to improve the response to oxidative damage, including that due to exposure to the sun. Thus, new substances that include potent antioxidant capability are starting to be used systemically, for example orally.

UV-based skin damage can be divided into two major categories: 1) acute, including necrosis, erythema and inflammation, and 2) chronic, termed photoaging, and characterized by the appearance of wrinkles, changes in skin color and skin cancer. The acute effects of UV exposure are mainly caused by high energy-containing photons, which are relatively easy to stop using molecules or molecular

*Address correspondence to this author at the Dermatology Service, Memorial Sloan-Kettering Cancer Center, 160 East 53rd Street, New York, NY-10022 USA; Tel: 212610 0185; Fax: 212308 0530;

E-mail: gonzals6@mskcc.org complexes that absorb, reflect, or scatter high-energy UV photons. Consequently, the major components of most topical sunscreens include barrier components as described above. However, most sunscreens cannot stop the lowerenergy UV photons that cause photoaging. These photons do not cause erythema, but they can induce immunosupression as well as mutations in the DNA of the most exposed cells of the epidermis and superficial dermis. These effects are amplified by the increased oxidative damage that results from the energy transfer of these photons to destroy naturally-occurring photoprotective molecules in the skin as well as to produce reactive oxygen species (ROS). The consequences of increased oxidation include extracellular matrix (e.g. collagen) deterioration, cellular apoptosis, plasma membrane destruction, direct DNA damage and increased mutagenesis [1-5].

Visible light can also harm the skin if there is a previous skin condition, e.g. chronic actinic dermatosis, or erythropoietic porphiria. Current UV filters do not protect against visible light; opaque filters are required, including clothing or "old school" preparations of physical filters, such as $\mathrm{ZnO}$ or $\mathrm{TiO}_{2}$ ([6] and see below).

From these facts, it can be inferred that proactive strategies to combat oxidative damage are highly desirable. This concept underlies the possibility of using oral antioxidants to combat the effects of photoaging. Some of the new substances used as oral photoprotectives contain one, or many, antioxidant active principles that can stop UVinduced skin damage, or even collaborate to repair previously induced damage. Future scenarios in the treatment and prevention of sun-induced skin pathologies contemplate synergic protection conferred by complementation of topical and oral sunscreens. 


\section{THOU SHALL NOT PASS! PREVENTING UV PHOTONS FROM REACHING THE SKIN}

\section{Clothing and Glasses}

Appropriate clothing and sunglasses are basic tools to fight sun-induced damage from both the UV and visible parts of the spectrum. The American Society of Photobiology and the American Academy of Dermatology have highlighted the importance of the use of adequate cloths, hats and eyewear to protect from UV radiation. Clothing photoprotection directly depends on thickness (thicker is usually better), color (reflective colors, such as white), moisture and tightness. Highly efficient photoprotective textiles are available, e.g. nylon made from BASF fibers, which has $\mathrm{TiO} 2$ particles embedded in the fabric. Also, some laundry products can endow or enhance photoprotection. For example, Rit Sun Guard ${ }^{\circledR}$ contains Tinosorb ${ }^{\circledR} \mathrm{FD}$, which is a UVA/UVB filter. Hats protect the scalp, forehead and neck, whereas gloves can prevent the appearance of lentigo on the hands, which has important cosmetic implications [7].

Solar erythema in the eyes often appears as "pink eye" (inflammation of the conjunctiva). In more severe cases, it can cause solar keratitis and irreversible damage to the vision $[8,9]$. Chronic damage includes cataracts and macular degeneration [3, 4]. Interestingly, use of appropriate goggles significantly decreases the risk of these events. There are well-defined, FDA-approved parameters for sunglasses: less than $0.001 \%$ of photons between $200-320 \mathrm{~nm}$ are accepted through the protective material, whereas the percentage is $<0.01 \%$ for less damaging wavelengths $(320-400 \mathrm{~nm})[10]$.

\section{Topical Sunscreens}

Topical sunscreens include substances: 1) that reflect or scatter UV photons, 2) that absorb them, preventing their incidence on the cells of the skin acceptors; 3) substances with antioxidant properties. The main goals are to protect against UVB radiation [11] and long-wavelength UVA radiation [12]; scavenge ROS; activate cellular repair systems, including DNA repair (Table 1).

Their activity is established according to their SPF (Sun Protection Factor), which is a measurement of their capability to stop UV photons: higher SPF means higher efficiency. A sunscreen SPF is usually measured using solarsimulated radiation (SSR) and a defined sunscreen application density $\left(2 \mathrm{mg} \cdot \mathrm{cm}^{-2}\right)$, and calculated according to the following formula:

Minimal Erythema Dose (MED) with sunscreen

$\mathrm{SPF}=\frac{\text { MED without sunscreen }}{\text { Men }}$

Other parameters utilized are: 1) Ery-PF (Erythema protection factor), which only takes into account the erythematous response after 24 hours; 2) PFA (Protection Against UVA), which is mainly used in the European Union; 3) Immune protection factor, for which there is no standardized protocol. One of the most utilized is the suppression of contact hypersensitivity by UV [13]. Additionally, sunscreens should (and some are) be tested for their antimutagenic and antioxidant properties.
Table 1. Main Photoprotector Groups

\begin{tabular}{|c|c|c|}
\hline \multicolumn{3}{|c|}{ Topical Photoprotective Agents } \\
\hline \multirow[t]{3}{*}{ a) } & \multicolumn{2}{|c|}{ Physical blockers } \\
\hline & \multicolumn{2}{|c|}{$\begin{array}{l}\text { Physical blockers } \\
\text { i) Zinc oxide }(\mathrm{ZnO})\end{array}$} \\
\hline & \multicolumn{2}{|c|}{ ii) Titanium dioxide $\left(\mathrm{TiO}_{2}\right]$} \\
\hline \multirow[t]{9}{*}{ b) } & \multicolumn{2}{|c|}{ Chemical and biological filtres } \\
\hline & \multicolumn{2}{|c|}{ i) Cinnamates } \\
\hline & \multirow[t]{3}{*}{ ii) } & Benzophenones \\
\hline & & - $\quad$ Oxybenzone \\
\hline & & - Avobenzone \\
\hline & iii) & Mexoryl SX \\
\hline & iv) & Mexoryl XL \\
\hline & v) & Tinosorb M \\
\hline & vi) & Tinosorb S \\
\hline \multirow[t]{20}{*}{ c) } & \multicolumn{2}{|c|}{ Antioxidants } \\
\hline & i) & \\
\hline & \multicolumn{2}{|r|}{ Polyphenolics } \\
\hline & & - $\quad$ Flavonoids \\
\hline & & - $\quad$ Green tea Extract \\
\hline & & - $\quad$ Astaxantin \\
\hline & iii) & Anthocyanins and tannins \\
\hline & iv) & Pycnogenol $^{\mathbb{B}}$ (French Maritime pinus extract $^{-}$ \\
\hline & v) & Fernblock $^{\circledR}$ (Polypodium leucotomos extract) \\
\hline & vi) & Others \\
\hline & & \multirow{10}{*}{$\begin{array}{ll}\text { - } & \text { Diydroxyacetone } \\
\text { - } & \text { Caffeine and caffeine sodium benzoate } \\
\text { - } & \text { Polygonum multiflorum thumb } \\
\text { - } & \text { N-(4-pyridoxylmethylene)-l-serine } \\
\text { - } & \text { Creatine } \\
\text { - } & \text { Idebenone } \\
\text { - } & \text { COX-2 inhibitors } \\
\text { - } & \text { DNA repair systems } \\
& \text { - Photolyase } \\
\text { - T4 endonuclease } \\
\text { - }\end{array}$} \\
\hline & & \\
\hline & & \\
\hline & & \\
\hline & & \\
\hline & & \\
\hline & & \\
\hline & & \\
\hline & & \\
\hline & & \\
\hline
\end{tabular}

2) Oral Photoprotective Agents

a) Vitamin derivatives

b) Dietary animal and botanic extracts

i) Genistein

ii) $\quad \omega 3$ polyunsaturated fatty acids

iii) Fernblock ${ }^{\circledR}$ (Polypodium leucotomos extract)

iv) Green teat polyphenols

High SPF sunscreens always contain a physical filter and at least two organic filters; one with optimal screening for UVB wavelengths and the other for UVA photons.

Topical sunscreens are presented as ointments, lotions, creams or sprays. Due to their ease of use, they are the most common photoprotective measure in environments of high exposure, e.g. seaside, mountain and countries with with low incidence of rain, e.g. countries in Oceania. Population studies have been conducted in some of these countries. For example, a study in Australia showed that consistent use of sunscreens ( $\mathrm{SPF} \geq 15$ ) significantly reduced the occurrence of some types of skin cancers [14]. A major caveat of most of these studies is that they fail to address the long-term effect of sunscreens in preventing photoaging. A few studies are emerging on the use of sunscreens to prevent photoaging. An early clinical trial in humans showed that use of a sunscreen $(\mathrm{SPF}=29)$ for two years reduced photoaging [15]; recently, sunscreens containing Mexoryl SX were found to reduce wrinkle depth in long-term studies [16]. However, these 
studies need to be standardized for future use as a general screening for topical sunscreens and to avoid false claims on efficacy.

\section{Components of Topical Sunscreens}

- $\quad$ Physical blockers: Blocking agents are made of big particles (diameter is $\sim 0.1-1 \mu \mathrm{m}$ ) that scatter, reflect or absorb solar radiation in the UV, visible and even infrared wavelengths. By far, the two most common physical blockers are zinc oxide $(\boldsymbol{Z n O})$ and titanium dioxide $\left(\mathrm{TiO}_{2}\right)$. Microfine zinc oxide is a better blocker than titanium dioxide [17]. However, both components are somewhat photosensitive and can react with light, inhibiting their efficiency or even causing tissue damage [18]. In addition, microfine $\mathrm{ZnO}$ or $\mathrm{TiO} 2$ do not protect against visible light. To prevent this, both compounds are usually caged. The most common caging substances are dimethicone or silica [19]. Additional stabilizers include carnauba wax, which contains cinnamates that synergize with $\mathrm{TiO}_{2}$ resulting in stable solutions that can hold SPF up to 50 [20-22].

- Filters (chemical or biological): These include:

a) UVB filters: They are efficient (90\%) UVB blockers [23]. Cinnamates are frequently used in combination with other substances, e.g. salicylates, which are very stable and insoluble in water, which allows them to retain their properties once applied on the skin $[24,25]$. Salicylates can also be used to dissolve other sunscreen ingredients, such as benzophenones [26].

b) UVA Filters: Most sunscreens protect well from UVB; however, these do not necessarily protect from UVA as well. Specific filters exist to absorb UVA photons, including oxybenzone (Bp-3; Eusolex 4360) and avobenzone (Parsol 1789) [23]. A major caveat is that these are easily oxidized and degraded.

c) Dual $\boldsymbol{U} \boldsymbol{V B} / \boldsymbol{U} \boldsymbol{V}$ filters: Newer filters have been developed that can absorb both UVA and UVB. Some examples include the Mexoryl series. Mexoryl SX is the commercial name of terephthalylidene dicamphor sulfonic acid. This compound is quite stable, and frequently used together with avobenzone in broad-spectrum sunscreens [1]. Several studies suggest a significant effect for Mexoryl SX-based formulations in preventing several aspects of photoaging [16, 27, 28]. Mexoryl XL is drometrizol trisiloxane and it absorbs UVB and UVA2 radiation. Mexoryl XL synergizes with Mexoryl SX for enhanced photoprotection [28]. Other dual filters include Tinosorb M (methylene-bisbenzotriazolyl tetramethylbutylphenol), which is made of microfine, water-soluble organic particles [25]; Tinosorb S (bisethylhexyloxyphenol methoxyphenyl triazine), which is another high-molecular mass broadband sunscreen filter (280-380 $\mathrm{nm}$ ) that can absorb and also reflect UV photons. It also synergizes with other blocking substances, such as OMC (2ethylhexyl-4-methoxycinnamate) and avobenzone [29]. Different biophysical techniques have been used to improve the efficacy and applicability of these filters, e.g. their encapsulation in sol-gel glass silica microcapsules of $\sim 1 \mu \mathrm{m}$ diameter [30]. These approaches decrease penetration beyond the epidermis and immunogenicity and improve photostability.

- Antioxidants: Antioxidants are commonly included in commercial sunscreens to reduce the photooxidative damage that results from UV-induced ROS production. These include several wellcharacterized vitamins including vitamins $\mathrm{C}, \mathrm{E}$ and $\beta$-carotene [31]. Other common substances are:

- Hydroxicinnamic acids, e.g. caffeic or ferulic acids. They prevent UVB-induced erythema in vivo and in vitro [24], and decrease UV-induced oxidative damage in skin cells and lymphocytes [32-34].

- Polyphenolics, e.g. flavonoids and phenolic acids. Several of them have antioxidant, antiinflammatory and antitumoral activities [35]. Several of these are used in sunscreens, including:

- Flavonoids: they are vegetal isoflavones endowed with antioxidant and antitumoral properties [36, 37]. Genistein is a specific inhibitor of protein tyrosine kinases and a phytoestrogen that effectively blocks UVB induced erythema [38, 39], as well as PUVA-induced photodamage and molecular alterations in hairless mouse skin $[40,41]$. It also bears antiphotocarcinogenic and antiphotoaging properties [39]. Silymarin is a plant flavonoid isolated from the seeds of milk thistle (Silybum marianum). It is a combination of of silybin, silydianin and silychristin that prevents ultraviolet lightinduced immune suppression and oxidative stress in a mouse model [42]. Equol can be purified from red clover (Trifolium pretense) in its precursor form, daidzein [43], and also from Punica granatum [44]. Equol protects from UV erythema and may prevent photocarcinogenesis [45, 46] and photoaging [47]. Quercetin is a very potent antioxidant used to successfully inhibit UVB-induced skin damage in rodent models [48, 49]. Apigenin decreases UVinduced skin tumorigenesis and inhibits tumor cell growth in vitro [50, 51]. Its mechanism includes inhibition of UVinduced upregulation of COX-2 [52]. 
- Green tea polyphenols (GTPP) is used to refer to several potent antioxidants that appear in green tea leaves. The most abundant is epigallocatechin-3-gallate (EGCG). EGCG reduces lipid peroxidation induced by UVB, and also decreases UVA-induced skin damage and immunosupression [53]. EGCG inhibits activation of pro-inflammatory transcription factors such as AP-1 and NF$\kappa \mathrm{B}$, collagenase expression and collagen cross-linking [54, 55]. Due to its intrinsic instability on skin, it needs to be mixed with butylated hydroxytoluene [56].

- $\quad$ Resveratrol is a polyphenolic phytoalexin present in several fruits, particularly grapes. Its topical use on hairless mice before UVB irradiation decreased erythema, ROS production and inflammation $[57,58]$. Its effect on delaying UV-induced tumorigenesis has also been reported [59].

- Astaxanthin is a natural xantophilic pigment that sequesters ROS and thus inhibits accumulation of free polyamines induced by UVA [60]. It also attenuates the UVA-induced up-regulation of matrix metalloproteinases and elastase in human dermal fibroblasts [61].

- Anthocyanins and tannins are present in several fruits, e.g. grapes or pears, and are endowed with antioxidant and anti-inflammatory properties. Used topically, they protect against the adverse effects of UV radiation, inhibiting UVB-dependent activation of NF- $\mathrm{B}$, MAP kinase and COX-2 pathways downstream of the signaling kinases MKK4, MEK1, and Raf-1 [62, 63].

- Pycnogenol $^{\circledR}$ is an extract of French maritime pine (Pinus pinaster Ait). It bears antioxidant, antiinflammatory and anticarcinogenic properties. Pycnogenol prevents UV-induced erythema as well as longer-term effects, such as immunosuppression and tumor formation [64, 65]. It also possesses regenerative skin properties [66], and prevents UVB-induced photoaging [67].

- Fernblock $^{\circledR}$ is an extract obtained from the fern Polypodium leucotomos. Topical application of Polypodium leucotomos extract (PL) inhibited UVB- and PUVA therapy-induced erythema in vivo [68]. PL is a potent antioxidant and has shown immunomodulating capability and inhibition of proinflammatory cytokines, such as TNF- $\alpha$ or IL-6 [69]. PL also inhibits the depletion of Langerhans cells induced by irradiation with UV light and PUVA therapy $[68,70,71]$ and reduces chronic elastosis and matrix metalloprotease expression [72, 73].

- Other photoprotective agents: We include miscellanea of compounds that have been used in different skin formulations. Some are:
- Dihydroxyacetone is a photoprotective agent that provides SPF 3-4 and protects against UVA photons [74]. Its main drawback is that it tints the skin and rare cases of contact dermatitis have been reported [75].

- Caffeine and caffeine sodium benzoate (SB) inhibit UVB-induced apoptosis. Additional studies have shown that caffeine-SB strongly inhibited UVB-induced carcinogenesis [76].

- Polygonum multiflorum thumb (PM) is an extract that possesses antibacterial properties. PM decreases oxidative stress induced by UVB irradiation [77].

- $\quad$ N-(4-pyridoxylmethylene)-L-serine (PYSer) is an antioxidant that suppresses iron-catalyzed ROS generation, and has shown promise in the treatment of UVB-induced photoaging [78].

- Creatine is a metabolic reservoir of energy in the muscle. It has been suggested that boosting the energy metabolism in the skin may improve skin aging and photoaging [79]. Consistently, topical use of creatine has been shown to decrease UV-induced damage in vitro and in vivo [80], and postulates it use to fight photoaging [81].

- Idebenone is a synthetic analog of coenzyme Q10 [82, 83]. A clinical study using a compound based on idebenone has suggested its efficacy in preventing photoaging [84], but other studies have suggested otherwise $[85,86]$. In addition, cases of contact dermatitis have been documented [87].

- COX-2 inhibitors: COX-2 (cyclooxygenase-2) is a metabolic enzyme linked to tumorigenesis and cancer progression. Consequently, COX-2 makes an excellent target for the development of antitumor drugs, which has turned out a bumpy road due to unforeseen side effects [88]. Regarding their topical use, celecoxib, a COX-2 inhibitor, has been shown to decrease UVBmediated erythema, inflammation and prostaglandin E2 $\left(\mathrm{PGE}_{2}\right)$ production $[89,90]$. It also inhibited UVB-induced papilloma formation [91] as well as the appearance of skin tumors after adoptive transfer of tumor cells [92].

- DNA repair enzymes constitute an emerging approach to enhance DNA repair after UV exposure. Some examples are:

- $\quad$ Photolyase is isolated from the cyanobacteria Anacystis nidulans. It promotes DNA repair and also decreases the number of UV-induced thymidine dimers [93, 94].

- $\quad$ T4 endonuclease has been assayed in patients with xeroderma pigmentosum [95, 96]. Treatment with a liposomal preparation of $\mathrm{T} 4$ endonuclease, T4N5, prevents sunburn and local 
suppression of contact- and delayed-type hypersensitivy [95, 97].

- DNA oligonucleotides can enhance the cellular response to subsequent UV irradiation, regardless the existence of previous DNA damage [98]. The most commonly assayed are thymidine dinucleotides as well as homologues of the telomere 3-prime overhang sequence ( $\mathrm{T}$ oligos). The latter exhibited enhanced melanogenesis and increased DNA repair in response to UV irradiation [99].

- $\quad$ AC-11 (C-Med-100) is obtained from cat's claw (Uncaria tomentosa). It promotes DNA repair (8-hydroxyguanine and strand breaks) after UVB exposure. Possible mechanisms include enhanced base excision repair or an inherent antioxidant effect. A single-blind, right side-left side beach sun exposure pilot study described a significant decrease in erythema and blistering by application of $0.5 \%$ topical AC- 11 with an SPF-15 sunscreen compared to application of SPF-15 sunscreen alone [100].

\section{THE ROAD LESS TAKEN: ORAL PHOTOPROTEC- TIVE AGENTS}

Oral photoprotection is a novel approach to skin care. Evidently, they cannot be used in lieu of topical sunscreens, as they do not prevent erythema but they complement their use by preventing photoaging and photocarcinogenesis. The amount of mechanistic information on their effects is still limited, but they are believed to increase the basal threshold of systemic antioxidant, actively collaborating in the refreshing of the skin natural antioxidant systems [101, 102]. Different active principles have been assayed for their oral photoprotective effect (Table 1). These are:

- Vitamin derivatives: They include:

- Carotenoids. Lycopene is the major carotenoid present in tomatoes and a very efficient singlet oxygen quencher. Recent studies have suggested beneficial photoprotective effects [103]. Lutein and zeaxanthin are xanthophyllic carotenoids that exhibit a moderate photoprotective effect in combination with topical application [104].

- Tocopherol and ascorbate exhibit moderate oral photoprotective effect when used in combination [105]; interestingly, a combination of lycopene, beta-carotene, alpha-tocopherol and selenium yeast reduced UV-induced damage [106]. Other combinations include Seresis ${ }^{\circledR}$, which contains carotenoids ( $\beta$-carotene and lycopene), ascorbate, tocopherol, selenium yeast and proanthocyanidins. Oral use of Seresis ${ }^{\circledR}$ delays the onset of UVBinduced erythema and inhibits the expression of matrix metalloproteinases, postulating an effect on photoaging [107].

- Dietary animal and botanical extracts: Their composition is rather heterogenenous, but most contain dietary flavonoids and phenolics. Some examples include:
- Genistein, which can be used as a dietary complement as well as in topical formulations (see above). Oral genistein decreases UVBinduced skin photoaging and tumorigenesis in a rodent model [39], postulating its use as a natural cancer preventive [108].

- $\quad \omega-3$ polyunsaturated fatty acids are a popular dietary supplement obtained from fish oil. Regarding their use as oral skin photoprotectors, high doses have been shown to decrease UVBinduced erythema and inflammation [109].

- Polypodium leucotomos extract (PL) can also be administered orally with very low toxicity. In addition to its antioxidant properties, PL can exert immunomodulatory effects. Oral PL scavenges free radicals and reactive oxygen species such superoxide anion, singlet oxygen, hydroxyl radical and hydrogen peroxide, and prevents lipid peroxidation [110, 111]. Oral administration also induced photoprotection against UVB radiation and during PUVA therapy without significantly affecting the efficacy of the treatment [70, 71]. Supplementation with PL significantly decreased erythema and depletion of Langerhans cells $[70,71]$. PL also prevents oxidative DNA damage (8-hydroxyguanine) and accelerates repair of thymine dimers $[71,112]$. In addition, it also inhibited trans-urocanic acid photoinduced isomerization and inactivation [113]. Analysis of its in vivo and in vitro protective effects have revealed several molecular mechanisms of action [68, 114, 115], including abrogation of UV-induced TNF- $\alpha$ and nitric oxide (NO) production [116]; potentiation of the endogenous antioxidant response [117]; inhibition of photoimmunosupression [118]; and modulation of the inflammatory response [112]. A recent study notes that oral administration reduces UVA-induced cyclobutane pyrimidine dimer deletions and mitochondrial DNA damage [119].

- Green tea polyphenols (GTPPs), e.g. epigallocatechin-3-gallate (EGCG). Oral use of EGCG prevents UV-induced skin tumorigenesis in mice. Several mechanisms underlie this effect, e.g. induction of interleukin 12, which prevents immunosupression and boosts DNA repair through excision repair mechanisms dependent; inhibition of angiogenic factors and stimulation of $\mathrm{T}$ cell-dependent cytotoxicity and tumor cell clearance [120]. Oral GTPPs can also decrease UV-induced expression of skin matrix metalloproteinases, postulating an effect in photoaging [121].

\section{CONCLUDING REMARKS AND FUTURE PERSPEC- TIVES}

This review offers a non-comprehensive account of several compounds with proven effect in photoprotection. Most of the topical compounds used topically are well 
proven tools to prevent erythema and the acute deleterious effects of UV exposure; However, the jury is still out regarding their efficacy in preventing chronic damage and photoaging. On the other hand, oral photoprotectives exert often modest effects. It is necessary to mention that they are not meant to be silver bullets in photoprotection, i.e. they cannot and are not intended to substitute sunscreens or to increase the threshold of what is considered healthy exposure to the sun. It is the general consensus that they are intended to fight the long term effects of UV exposure, particularly photoaging and skin tumorigenesis. Future studies will undoubtedly reveal the complementary effect of topical and oral photoprotection.

The mechanisms of photoprotection of most of these compounds are not fully defined yet; most of them are based on powerful antioxidant activities; others promote regeneration through yet-unknown mechanisms, making this an active and attractive field for basic and clinical research. Therefore, further clinical trials will be required to validate the preventive and therapeutic value of these products. In summary, oral sunscreens have a demonstrated therapeutic value in the prevention and treatment of sun damage, and are likely in their way to become a mainstream method of protection that complements traditional screening methods.

\section{ACKNOWLEDGMENTS}

Salvador Gonzalez is a consultant for Industrial Farmaceutica Cantabria (IFC), which supports some of the studies reviewed in this article. This work has been partially supported by a grant from the Carlos III Health Institute, Ministry of Science and Innovation, Spain (PS09/01099).

\section{REFERENCES}

[1] Seite S, Colige A, Piquemal-Vivenot P, et al. A full-UV spectrum absorbing daily use cream protects human skin against biological changes occurring in photoaging. Photodermatol Photoimmunol Photomed 2000; 16(4): 147-55.

[2] Moyal D. Immunosuppression induced by chronic ultraviolet irradiation in humans and its prevention by sunscreens. Eur $\mathbf{J}$ Dermatol 1998; 8(3): 209-11.

[3] van der Pols JC, Xu C, Boyle GM, Parsons PG, Whiteman DC, Green AC. Expression of p53 tumor suppressor protein in sunexposed skin and associations with sunscreen use and time spent outdoors: a community-based study. Am J Epidemiol 2006; 163(11): 982-8.

[4] Al Mahroos M, Yaar M, Phillips TJ, Bhawan J, Gilchrest BA. Effect of sunscreen application on UV-induced thymine dimers. Arch Dermatol 2002; 138(11): 1480-5.

[5] Bernerd F, Vioux C, Asselineau D. Evaluation of the protective effect of sunscreens on in vitro reconstructed human skin exposed to UVB or UVA irradiation. Photochem Photobiol 2000; 71(3): 314-20.

[6] Kaye ET, Levin JA, Blank IH, Arndt KA, Anderson RR. Efficiency of opaque photoprotective agents in the visible light range. Arch Dermatol 1991; 127(3): 351-5.

[7] Menter JM, Hatch KL. Clothing as solar radiation protection. Curr Probl Dermatol 2003; 31:50-63.

[8] Cullen AP. Photokeratitis and other phototoxic effects on the cornea and conjunctiva. Int J Toxicol 2002; 21(6): 455-64.

[9] Young RW. The family of sunlight-related eye diseases. Optom Vis Sci 1994; 71(2): 125-44.

[10] Dain SJ. Sunglasses and sunglass standards. Clin Exp Optom 2003; 86(2): 77-90.

[11] Sano T, Kume T, Fujimura T, Kawada H, Moriwaki S, Takema Y. The formation of wrinkles caused by transition of keratin intermediate filaments after repetitive UVB exposure. Arch Dermatol Res 2005; 296(8): 359-65.
[12] Krutmann J. Ultraviolet A radiation-induced biological effects in human skin: relevance for photoaging and photodermatosis. J Dermatol Sci 2000; 23 Suppl 1: S22-6.

[13] Young AR. Methods used to evaluate the immune protection factor of a sunscreen: advantages and disadvantages of different in vivo techniques. Cutis 2004; 74(5 Suppl): 19-23.

[14] Neale R, Williams G, Green A. Application patterns among participants randomized to daily sunscreen use in a skin cancer prevention trial. Arch Dermatol 2002; 138(10): 1319-25.

[15] Boyd AS, Naylor M, Cameron GS, Pearse AD, Gaskell SA, Neldner KH. The effects of chronic sunscreen use on the histologic changes of dermatoheliosis. J Am Acad Dermatol 1995; 33(6): 941-6.

[16] Fourtanier A, Moyal D, Seite S. Sunscreens containing the broadspectrum UVA absorber, Mexoryl SX, prevent the cutaneous detrimental effects of UV exposure: a review of clinical study results. Photodermatol Photoimmunol Photomed 2008; 24(4): 16474.

[17] Pinnell SR, Fairhurst D, Gillies R, Mitchnick MA, Kollias N Microfine zinc oxide is a superior sunscreen ingredient to microfine titanium dioxide. Dermatol Surg 2000; 26(4): 309-14.

[18] Wamer WG, Yin JJ, Wei RR. Oxidative damage to nucleic acids photosensitized by titanium dioxide. Free Radic Biol Med 1997; 23(6): 851-8

[19] Van Reeth I. Beyond skin feel: innovative methods for developing complex sensory profiles with silicones. J Cosmet Dermatol 2006; 5(1): 61-7.

[20] Villalobos-Hernandez JR, Muller-Goymann CC. Novel nanoparticulate carrier system based on carnauba wax and decyl oleate for the dispersion of inorganic sunscreens in aqueous media. Eur J Pharm Biopharm 2005; 60(1): 113-22.

[21] Villalobos-Hernandez JR, Muller-Goymann CC. Sun protection enhancement of titanium dioxide crystals by the use of carnauba wax nanoparticles: the synergistic interaction between organic and inorganic sunscreens at nanoscale. Int J Pharm 2006; 322(1-2): 161-70.

[22] Villalobos-Hernandez JR, Muller-Goymann CC. In vitro erythemal UV-A protection factors of inorganic sunscreens distributed in aqueous media using carnauba wax-decyl oleate nanoparticles. Eur J Pharm Biopharm 2007; 65(1): 122-5

[23] Lowe NJ. An overview of ultraviolet radiation, sunscreens, and photo-induced dermatoses. Dermatol Clin 2006; 24(1): 9-17.

[24] Saija A, Tomaino A, Trombetta D, De Pasquale A, Uccella N, Barbuzzi $\mathrm{T}$, et al. In vitro and in vivo evaluation of caffeic and ferulic acids as topical photoprotective agents. Int J Pharm 2000; 199(1): 39-47.

[25] Kullavanijaya P, Lim HW. Photoprotection. J Am Acad Dermatol 2005; 52(6): 937-58; quiz 959-62.

[26] Chatelain E, Gabard B, Surber C. Skin penetration and sun protection factor of five UV filters: effect of the vehicle. Skin Pharmacol Appl Skin Physiol 2003; 16(1): 28-35.

[27] Seite S, Moyal D, Richard S, de Rigal J, Leveque JL, Hourseau C, et al. Mexoryl SX: a broad absorption UVA filter protects human skin from the effects of repeated suberythemal doses of UVA. J Photochem Photobiol B 1998; 44(1): 69-76.

[28] Moyal D. Prevention of ultraviolet-induced skin pigmentation Photodermatol Photoimmunol Photomed 2004; 20(5): 243-7.

[29] Chatelain E, Gabard B. Photostabilization of butyl methoxydibenzoylmethane (Avobenzone) and ethylhexyl methoxycinnamate by bis-ethylhexyloxyphenol methoxyphenyl triazine (Tinosorb S), a new UV broadband filter. Photochem Photobiol 2001; 74(3): 401-6.

[30] Lapidot N, Gans O, Biagini F, Sosonkin L, Rottman C. Advanced sunscreens: UV absorbers encapsulated in sol-gel glass microcapsules. J Sol-Gel Sci Technol 2003; 26: 67-72.

[31] Pinnell SR. Cutaneous photodamage, oxidative stress, and topical antioxidant protection. J Am Acad Dermatol 2003; 48(1): 1-19; quiz 20-2.

[32] Prasad NR, Jeyanthimala K, Ramachandran S. Caffeic acid modulates ultraviolet radiation- $\mathrm{B}$ induced oxidative damage in human blood lymphocytes. J Photochem Photobiol B 2009; 95(3): 196-203.

[33] Di Domenico F, Perluigi M, Foppoli C, Blarzino C, Coccia R, De Marco F, et al. Protective effect of ferulic acid ethyl ester against oxidative stress mediated by UVB irradiation in human epidermal melanocytes. Free Radic Res 2009; 43(4): 365-75. 
[34] Kang NJ, Lee KW, Shin BJ, et al. Caffeic acid, a phenolic phytochemical in coffee, directly inhibits Fyn kinase activity and UVB-induced COX-2 expression. Carcinogenesis 2009; 30(2): 321-30.

[35] Lambert JD, Hong J, Yang GY, Liao J, Yang CS. Inhibition of carcinogenesis by polyphenols: evidence from laboratory investigations. Am J Clin Nutr 2005; 81(1 Suppl): 284S-291S.

[36] Cazarolli LH, Zanatta L, Alberton EH, Figueiredo MS, Folador P, Damazio RG, et al. Flavonoids: prospective drug candidates. Mini Rev Med Chem 2008; 8(13): 1429-40.

[37] Dinkova-Kostova AT. Phytochemicals as protectors against ultraviolet radiation: versatility of effects and mechanisms. Planta Med 2008; 74(13): 1548-59.

[38] Afaq F, Mukhtar H. Botanical antioxidants in the prevention of photocarcinogenesis and photoaging. Exp Dermatol 2006; 15(9): 678-684.

[39] Wei H, Saladi R, Lu Y, et al. Isoflavone genistein: photoprotection and clinical implications in dermatology. J Nutr 2003; 133(11 Suppl 1): 3811S-3819S.

[40] Liu Z, Lu Y, Lebwohl M, Wei H. PUVA (8-methoxy-psoralen plus ultraviolet A) induces the formation of 8-hydroxy-2'deoxyguanosine and DNA fragmentation in calf thymus DNA and human epidermoid carcinoma cells. Free Radic Biol Med 1999; 27(1-2): 127-33.

[41] Shyong EQ, Lu Y, Lazinsky A, Saladi RN, Phelps RG, Austin LM, et al. Effects of the isoflavone 4',5,7-trihydroxyisoflavone (genistein) on psoralen plus ultraviolet A radiation (PUVA)induced photodamage. Carcinogenesis 2002; 23(2): 317-21.

[42] Katiyar SK. Treatment of silymarin, a plant flavonoid, prevents ultraviolet light-induced immune suppression and oxidative stress in mouse skin. Int J Oncol 2002; 21(6): 1213-22.

[43] Widyarini S, Spinks N, Husband AJ, Reeve VE. Isoflavonoid compounds from red clover (Trifolium pratense) protect from inflammation and immune suppression induced by UV radiation. Photochem Photobiol 2001; 74(3): 465-70.

[44] Park HM, Moon E, Kim AJ, et al. Extract of Punica granatum inhibits skin photoaging induced by UVB irradiation. Int $\mathrm{J}$ Dermatol 2010; 49(3): 276-82.

[45] Lin JY, Tournas JA, Burch JA, Monteiro-Riviere NA, Zielinski J. Topical isoflavones provide effective photoprotection to skin. Photodermatol Photoimmunol Photomed 2008; 24(2): 61-6.

[46] Widyarini S, Husband AJ, Reeve VE. Protective effect of the isoflavonoid equol against hairless mouse skin carcinogenesis induced by UV radiation alone or with a chemical cocarcinogen. Photochem Photobiol 2005; 81(1): 32-7.

[47] Reeve VE, Widyarini S, Domanski D, Chew E, Barnes K. Protection against photoaging in the hairless mouse by the isoflavone equol. Photochem Photobiol 2005; 81(6): 1548-53.

[48] Casagrande R, Georgetti SR, Verri WA Jr, Dorta DJ, dos Santos $\mathrm{AC}$, Fonseca MJ. Protective effect of topical formulations containing quercetin against UVB-induced oxidative stress in hairless mice. J Photochem Photobiol B 2006; 84(1): 21-7.

[49] Vicentini FT, Simi TR, Del Ciampo JO, et al. Quercetin in w/o microemulsion: in vitro and in vivo skin penetration and efficacy against UVB-induced skin damages evaluated in vivo. Eur J Pharm Biopharm 2008; 69(3): 948-57.

[50] Wei H, Tye L, Bresnick E, Birt DF. Inhibitory effect of apigenin, a plant flavonoid, on epidermal ornithine decarboxylase and skin tumor promotion in mice. Cancer Res 1990; 50(3): 499-502.

[51] Wang W, Heideman L, Chung CS, Pelling JC, Koehler KJ, Birt DF. Cell-cycle arrest at G2/M and growth inhibition by apigenin in human colon carcinoma cell lines. Mol Carcinog 2000; 28(2): 10210 .

[52] Tong X, Van Dross RT, Abu-Yousif A, Morrison AR, Pelling JC. Apigenin prevents UVB-induced cyclooxygenase 2 expression: coupled mRNA stabilization and translational inhibition. Mol Cell Biol 2007; 27(1): 283-96.

[53] Katiyar SK, Vaid M, van Steeg H, Meeran SM. Green Tea Polyphenols Prevent UV-Induced Immunosuppression by Rapid Repair of DNA Damage and Enhancement of Nucleotide Excision Repair Genes. Cancer Prev Res (Phila Pa) 2010.

[54] Rutter K, Sell DR, Fraser N, et al. Green tea extract suppresses the age-related increase in collagen crosslinking and fluorescent products in C57BL/6 mice. Int J Vitam Nutr Res 2003; 73(6): 45360 .
[55] Xia J, Song X, Bi Z, Chu W, Wan Y. UV-induced NF-kappaB activation and expression of IL-6 is attenuated by (-)epigallocatechin-3-gallate in cultured human keratinocytes in vitro. Int J Mol Med 2005; 16(5): 943-50.

[56] Dvorakova K, Dorr RT, Valcic S, Timmermann B, Alberts DS Pharmacokinetics of the green tea derivative, EGCG, by the topical route of administration in mouse and human skin. Cancer Chemother Pharmacol 1999; 43(4): 331-5.

[57] Afaq F, Adhami VM, Ahmad N. Prevention of short-term ultraviolet $\mathrm{B}$ radiation-mediated damages by resveratrol in SKH-1 hairless mice. Toxicol Appl Pharmacol 2003; 186(1): 28-37.

[58] Nichols JA, Katiyar SK. Skin photoprotection by natural polyphenols: anti-inflammatory, antioxidant and DNA repair mechanisms. Arch Dermatol Res 2010; 302(2): 71-83.

[59] Aziz MH, Reagan-Shaw S, Wu J, Longley BJ, Ahmad N. Chemoprevention of skin cancer by grape constituent resveratrol: relevance to human disease? Faseb J 2005; 19(9): 1193-5.

[60] Goto S, Kogure K, Abe K, Kimata Y, Kitahama K, Yamashita E, et al. Efficient radical trapping at the surface and inside the phospholipid membrane is responsible for highly potent antiperoxidative activity of the carotenoid astaxanthin. Biochim Biophys Acta 2001; 1512(2): 251-8.

[61] Suganuma K, Nakajima H, Ohtsuki M, Imokawa G. Astaxanthin attenuates the UVA-induced up-regulation of matrixmetalloproteinase-1 and skin fibroblast elastase in human dermal fibroblasts. J Dermatol Sci 2010; 58(2): 136-42.

[62] Kwon JY, Lee KW, Kim JE, et al. Delphinidin suppresses ultraviolet B-induced cyclooxygenases-2 expression through inhibition of MAPKK4 and PI-3 kinase. Carcinogenesis 2009; 30(11): 1932-40.

[63] Kim JE, Kwon JY, Seo SK, et al. Cyanidin suppresses ultraviolet B-induced COX-2 expression in epidermal cells by targeting MKK4, MEK1, and Raf-1. Biochem Pharmacol 2010; 79(10): 1473-82.

[64] Saliou C, Rimbach G, Moini H, et al. Solar ultraviolet-induced erythema in human skin and nuclear factor-kappa-B-dependent gene expression in keratinocytes are modulated by a French maritime pine bark extract. Free Radic Biol Med 2001; 30(2): 154 60 .

[65] Bito T, Roy S, Sen CK, Packer L. Pine bark extract pycnogenol downregulates IFN-gamma-induced adhesion of $\mathrm{T}$ cells to human keratinocytes by inhibiting inducible ICAM-1 expression. Free Radic Biol Med 2000; 28(2): 219-27.

[66] Sime S, Reeve VE. Protection from inflammation, immunosuppression and carcinogenesis induced by UV radiation in mice by topical Pycnogenol. Photochem Photobiol 2004; 79(2): 193-8.

[67] Cho HS, Lee MH, Lee JW, et al. Anti-wrinkling effects of the mixture of vitamin $\mathrm{C}$, vitamin $\mathrm{E}$, pycnogenol and evening primrose oil, and molecular mechanisms on hairless mouse skin caused by chronic ultraviolet B irradiation. Photodermatol Photoimmunol Photomed 2007; 23(5): 155-62.

[68] Gonzalez S, Pathak MA, Cuevas J, Villarubia VG, Fitzpatrick TB. Topical or oral administration with an extract of Polypodium leucotomos prevents acute sunburn and psolaren-induced phototoxic reactions as well as depletion of Langerhans cells in human skin. Photodermatol. Photoimmunol Photomed 1997; 13: 50-60.

[69] Brieva A, Guerrero A, Pivel JP. Immunomodulatory properties of an hydrophilic extract of Polypodium leucotomos. Inflammopharmacol 2002; 9: 361-371.

[70] Middelkamp-Hup MA, Pathak MA, Parrado C, et al. Orally administered Polypodium leucotomos extract decreases psoralenUVA-induced phototoxicity, pigmentation, and damage of human skin. J. Am. Acad. Dermatol. 2004; 50(1): 41-49.

[71] Middelkamp-Hup MA, Pathak MA, Parrado C, Goukassian D, Rius-Diaz F, Mihm MC, et al. Oral Polypodium leucotomos extract decreases ultraviolet-induced damage of human skin. J Am Acad Dermatol 2004; 51(6): 910-918.

[72] Alcaraz MV, Pathak MA, Rius F, Kollias N, González S. An extract of Polypodium leucotomos appears to minimize certain photoaging changes in a hairless albino mouse animal model. Photodermatol. Photoimmunol Photomed 1999; 15: 120-126.

[73] Philips N, Conte J, Chen YJ, Natrajan P, Taw M, Keller T, et al. Beneficial regulation of matrixmetalloproteinases and their inhibitors, fibrillar collagens and transforming growth factor-beta 
by Polypodium leucotomos, directly or in dermal fibroblasts, ultraviolet radiated fibroblasts, and melanoma cells. Arch Dermatol Res 2009; 301(7): 487-495.

[74] Draelos ZD. Self-tanning lotions: are they a healthy way to achieve a tan? Am J Clin Dermatol 2002; 3(5): 317-8.

[75] Morren M, Dooms-Goossens A, Heidbuchel M, Sente F, Damas MC. Contact allergy to dihydroxyacetone. Contact Dermatitis 1991; 25(5): 326-7.

[76] Lu YP, Lou YR, Xie JG, et al. Caffeine and caffeine sodium benzoate have a sunscreen effect, enhance UVB-induced apoptosis, and inhibit UVB-induced skin carcinogenesis in SKH-1 mice. Carcinogenesis 2007; 28(1): 199-206.

[77] Hwang IK, Yoo KY, Kim DW, et al. An extract of Polygonum multiflorum protects against free radical damage induced by ultraviolet B irradiation of the skin. Braz J Med Biol Res 2006; 39(9): 1181-8

[78] Kitazawa M, Ishitsuka Y, Kobayashi M, et al. Protective effects of an antioxidant derived from serine and vitamin B6 on skin photoaging in hairless mice. Photochem Photobiol 2005; 81(4): 970-4.

[79] Blatt T, Lenz H, Koop U, et al. Stimulation of skin's energy metabolism provides multiple benefits for mature human skin. Biofactors 2005; 25(1-4): 179-85.

[80] Lenz H, Schmidt M, Welge V, et al. The creatine kinase system in human skin: protective effects of creatine against oxidative and UV damage in vitro and in vivo. J Invest Dermatol 2005; 124(2): 44352.

[81] Knott A, Koop U, Mielke H, et al. A novel treatment option for photoaged skin. J Cosmet Dermatol 2008; 7(1): 15-22.

[82] Farris P. Idebenone, green tea, and Coffeeberry extract: new and innovative antioxidants. Dermatol Ther 2007; 20(5): 322-9.

[83] Dong KK, Damaghi N, Kibitel J, Canning MT, Smiles KA, Yarosh DB. A comparison of the relative antioxidant potency of Lergothioneine and idebenone. J Cosmet Dermatol 2007; 6(3): 1838.

[84] McDaniel D, Neudecker B, Dinardo J, Lewis J, 2nd, Maibach H. Clinical efficacy assessment in photodamaged skin of $0.5 \%$ and 1.0\% idebenone. J Cosmet Dermatol 2005; 4(3): 167-73.

[85] Tournas JA, Lin FH, Burch JA, et al. Ubiquinone, idebenone, and kinetin provide ineffective photoprotection to skin when compared to a topical antioxidant combination of vitamins $\mathrm{C}$ and $\mathrm{E}$ with ferulic acid. J Invest Dermatol 2006; 126(5): 1185-7.

[86] Bruce S. Cosmeceuticals for the attenuation of extrinsic and intrinsic dermal aging. J Drugs Dermatol 2008; 7(2 Suppl): s17-22.

[87] Mc Aleer MA, Collins P. Allergic contact dermatitis to hydroxydecyl ubiquinone (idebenone) following application of anti-ageing cosmetic cream. Contact Dermatitis 2008; 59(3): 178-9.

[88] Psaty BM, Furberg CD. COX-2 inhibitors--lessons in drug safety. N Engl J Med 2005; 352(11): 1133-5.

[89] Fischer SM, Lo HH, Gordon GB, Seibert K, Kelloff G, Lubet RA, et al. Chemopreventive activity of celecoxib, a specific cyclooxygenase-2 inhibitor, and indomethacin against ultraviolet light-induced skin carcinogenesis. Mol Carcinog 1999; 25(4): 231240 .

[90] Zhan H, Zheng H. The role of topical cyclo-oxygenase-2 inhibitors in skin cancer: treatment and prevention. Am J Clin Dermatol 2007; 8(4): 195-200.

[91] Wilgus TA, Koki AT, Zweifel BS, Kusewitt DF, Rubal PA, Oberyszyn TM. Inhibition of cutaneous ultraviolet light Bmediated inflammation and tumor formation with topical celecoxib treatment. Mol Carcinog 2003; 38(2): 49-58.

[92] Fegn L, Wang Z. Topical chemoprevention of skin cancer in mice, using combined inhibitors of 5-lipoxygenase and cyclo-oxygenase2. J Laryngol Otol 2009; 123(8): 880-4.

[93] Stege H, Roza L, Vink AA, Grewe M, Ruzicka T, Grether-Beck S, et al. Enzyme plus light therapy to repair DNA damage in ultraviolet-B-irradiated human skin. Proc Natl Acad Sci USA 2000; 97(4): 1790-5.

[94] Essen LO, Klar T. Light-driven DNA repair by photolyases. Cell Mol Life Sci 2006; 63(11): 1266-77.

[95] Yarosh D, Klein J, O'Connor A, Hawk J, Rafal E, Wolf P. Effect of topically applied T4 endonuclease $\mathrm{V}$ in liposomes on skin cancer in xeroderma pigmentosum: a randomised study. Xeroderma Pigmentosum Study Group. Lancet 2001; 357(9260): 926-9.
[96] Zahid S, Brownell I. Repairing DNA damage in xeroderma pigmentosum: T4N5 lotion and gene therapy. J Drugs Dermatol 2008; 7(4): 405-8.

[97] Cafardi JA, Elmets CA. T4 endonuclease V: review and application to dermatology. Expert Opin Biol Ther 2008; 8(6): 829-38.

[98] Goukassian DA, Helms E, van Steeg H, van Oostrom C, Bhawan J, Gilchrest BA. Topical DNA oligonucleotide therapy reduces UVinduced mutations and photocarcinogenesis in hairless mice. Proc Natl Acad Sci USA 2004; 101(11): 3933-8.

[99] Arad S, Konnikov N, Goukassian DA, Gilchrest BA. T-oligos augment $\mathrm{UV}$-induced protective responses in human skin. Faseb J 2006; 20(11): 1895-7.

[100] Emanuel P, Scheinfeld N. A review of DNA repair and possible DNA-repair adjuvants and selected natural anti-oxidants. Dermatol Online J 2007; 13(3): 10

[101] Pattison DI, Davies MJ. Actions of ultraviolet light on cellular structures. Exs 2006(96): 131-57.

[102] DeBuys HV, Levy SB, Murray JC, Madey DL, Pinnell SR. Modern approaches to photoprotection. Dermatol Clin 2000; 18(4): 577-90.

[103] Stahl W, Heinrich U, Aust O, Tronnier H, Sies H. Lycopene-rich products and dietary photoprotection. Photochem Photobiol Sci 2006; 5(2): 238-42.

[104] Palombo P, Fabrizi G, Ruocco V, et al. Beneficial long-term effects of combined oral/topical antioxidant treatment with the carotenoids lutein and zeaxanthin on human skin: a double-blind, placebocontrolled study. Skin Pharmacol Physiol 2007; 20(4): 199-210.

[105] Eberlein-Konig B, Ring J. Relevance of vitamins C and E in cutaneous photoprotection. J Cosmet Dermatol 2005; 4(1): 4-9.

[106] Cesarini JP, Michel L, Maurette JM, Adhoute H, Bejot M Immediate effects of UV radiation on the skin: modification by an antioxidant complex containing carotenoids. Photodermatol Photoimmunol Photomed 2003; 19(4): 182-9.

[107] Greul AK, Grundmann JU, Heinrich F, Pfitzner I, Bernhardt J, Ambach A, et al. Photoprotection of UV-irradiated human skin: an antioxidative combination of vitamins $\mathrm{E}$ and $\mathrm{C}$, carotenoids, selenium and proanthocyanidins. Skin Pharmacol Appl Skin Physiol 2002; 15(5): 307-15.

[108] Gullett NP, Ruhul Amin AR, et al. Cancer prevention with natural compounds. Semin Oncol 2010; 37(3): 258-81.

[109] Rhodes LE, O'Farrell S, Jackson MJ, Friedmann PS. Dietary fishoil supplementation in humans reduces UVB-erythemal sensitivity but increases epidermal lipid peroxidation. J Invest Dermatol 1994; 103(2): 151-4.

[110] Gonzalez S, Pathak MA. Inhibition of ultraviolet-induced formation of reactive oxygen species, lipid peroxidation, erythema and skin photosensitization by Polypodium leucotomos. Photodermatol Photoimmunol Photomed 1996; 12: 45-56.

[111] Gomes AJ, Lunardi CN, Gonzalez S, Tedesco AC. The antioxidant action of Polypodium leucotomos extract and kojic acid: reactions with reactive oxygen species. Braz J Med Biol Res 2001; 34(11): 1487-1494

[112] Zattra E, Coleman C, Arad S, et al. Oral Polypodium leucotomos decreases UV-induced Cox-2 expression, inflammation, and enhances DNA repair in Xpc +/- mice. Am J Pathol 2009; 175 1952-1961.

[113] Capote R, Alonso-Lebrero JL, Garcia F, Brieva A, Pivel JP, Gonzalez S. Polypodium leucotomos extract inhibits trans-urocanic acid photoisomerization and photodecomposition. J Photochem Photobiol B 2006; 82(3): 173-9.

[114] Gonzalez S, Joshi PC, Pathak MA. Polypodium leucotomos extract as an antioxidant agent in the therapy of skin disorders. J Invest Dermatol 1994; 102: 651-659.

[115] Alonso-Lebrero JL, Domínguez-Jiménez C, Tejedor R, Brieva A, Pivel JP. Photoprotective properties of a hydrophilic extract of the fern Polypodium leucotomos on human skin cells. J Photochem Photobiol B 2003; 70: 31-37.

[116] Janczyk A, Garcia-Lopez MA, Fernandez-Penas P, et al. A Polypodium leucotomos extract inhibits solar-simulated radiationinduced TNF-alpha and iNOS expression, transcriptional activation and apoptosis. Exp Dermatol 2007; 16(10): 823-829.

[117] Mulero M, Rodriguez-Yanes E, Nogues MR, et al. Polypodium leucotomos extract inhibits glutathione oxidation and prevents Langerhans cell depletion induced by UVB/UVA radiation in a hairless rat model. Exp Dermatol 2008; 17: 653-658.

[118] Siscovick JR, Zapolanski T, Magro C, et al. Polypodium leucotomos inhibits ultraviolet $\mathrm{B}$ radiation-induced immunosup- 
pression. Photodermatol. Photoimm-unol. Photomed 2008; 24(3): 134-141.

[119] Villa A, Viera MH, Amini S, et al. Decrease of ultraviolet A lightinduced "common deletion" in healthy volunteers after oral Polypodium leucotomos extract supplement in a randomized clinical trial. J Am Acad Dermatol 2010; 62(3): 511-3.
[120] Katiyar S, Elmets CA, Katiyar SK. Green tea and skin cancer: photoimmunology, angiogenesis and DNA repair. J Nutr Biochem 2007; 18(5): 287-96.

[121] Vayalil PK, Mittal A, Hara Y, Elmets CA, Katiyar SK. Green tea polyphenols prevent ultraviolet light-induced oxidative damage and matrix metalloproteinases expression in mouse skin. J Invest Dermatol 2004; 122(6): 1480-7.

Received: September 25, 2010

Revised: December 11, 2010

Accepted: December 29, 2010

(C) Gonzalez et al.; Licensee Bentham Open.

This is an open access article licensed under the terms of the Creative Commons Attribution Non-Commercial License (http: //creativecommons.org/licenses/by$\mathrm{nc} / 3.0 /$ ) which permits unrestricted, non-commercial use, distribution and reproduction in any medium, provided the work is properly cited. 